\title{
KERONCONGKU, NGRONCONGI
}

\author{
Bayu Raditya Prabowo \\ Mahasiswa Pengkajian Seni Musik Pascasarjana ISI Surakarta \\ dapat dihubungi di bayustrato@gmail.com | 082225612040
}

\begin{abstract}
Keroncong music has a basic concept of musical achievement that is often expressed by keroncong artists with the word "ngroncongi". Ngroncongi is a term that refers to the Java language. Keroncong becomes the basic word, which at the beginning of the word is affixed "Ng" and at the end the word gets "- $i$ ", so initially keroncong is a noun, turning into an adjective after it turns into "ngroncongi". Ngroncongi is a musical aspect that becomes an indication of keroncong music characteristic. Ngroncongi will be achieved when it reaches the aesthetic and keroncong culture. Musicality which is "ngroncongi" is constructed by several musical elements such as, samen spelen; ngglali; nyendaren; mbesut; luk; gojek; isen-isen; mbanyumili; and sintiran. Those elements are synergized to accommodate the concept of "ngroncongi". The elements of rhythmic pattern are sintiran, mbanyumili, and gojek. The elements for ornamentation are ngglali; mbesut; luk; nyendaren; and isen-isen. While the element of "samen spelen" is for a musical interaction between players by giving each other musical communication. These elements found from the emissive knowledge of keroncong players who are represented in musical way to build musicality which is called "ngroncongi".
\end{abstract}

Kata kunci : Keroncong, Ngroncongi, Musikalitas

\section{Musikalitas yang Ngroncongi Dalam Musik Keroncong}

Musik keroncong sampai saat ini memiliki daya tarik tersendiri bagi para apresiatornya. Apresiasi masyarakat terhadap musik keroncong difasilitasi oleh beberapa panggung pertunjukkan, maupun media penyiaran yang secara khusus menyajikan musik keroncong. Hal ini dapat dilihat dari eksistensi kelompok musik keroncong yang telah mempunyai kredibilitas untuk tetap mempertahankan keberadaan musik keroncong. Adapula kelompok keroncong generasi baru yang dibentuk untuk turut melestarikan musik keroncong.

Apresiasi masyarakat mengenai musik keroncong yang mereka nikmati mengalami respon yang beragam. Keberagaman respon tersebut berasal dari sudut pandang penikmat musik keroncong, yang bukan berlatar belakang seniman 
keroncong, maupun seniman keroncong yang juga sebagai pelaku. Saat musik keroncong tersebut disajikan, muncul beberapa anggapan yang merujuk kepada persoalan musikalitasnya. Penikmat musik keroncong yang tidak memiliki latar belakang seniman keroncong mempunyai sudut pandang tersendiri dalam menilai musikalitasnya. Apa yang diungkapkan oleh musik itu melalui konstruk musiknya, menggunakan medium apa, dan cara bagaimana atau bagaimana sifatnya. Sebab, hakekat musikalitas adalah segala persoalan yang bersangkutan dengan masalahmasalah konstruk, medium, cara mengolah medium dan sifatnya. (Sunarto, 2006:76)

Kasus yang terjadi pada realitas adalah, penikmat musik mempunyai anggapan bahwa sajian musik keroncong yang diterima oleh telinga mereka ada yang terasa sangat keroncong, ada pula yang dianggap tidak memenuhi rasa keroncong. Penilaian yang dilakukan oleh para penikmat musik keroncong tersebut berdasar aspek instrumen yang digunakan, perannya dalam komposisi dan juga pola dasar musik keroncong yang telah melekat menjadi struktur musik keroncong.

Seniman keroncong justru mempunyai penilaian yang berbeda. Musik keroncong yang mereka apresiasi dapat mereka lihat rasa musikalnya. Penilaiannya tidak hanya merujuk pada instrumen apa yang digunakan, dan teknik permainan yang digunakan dalam musik keroncong. Seniman keroncong menilai sampai persoalan tingkat kedalaman rasa yang tidak disinggung atau dirasakan oleh penikmat musik keroncong. Apabila penikmat menilai gejala musik keroncong masih pada tingkat pola dasar permainan musik keroncong, seniman keroncong mempunyai kedalaman lebih, yakni sudah pada ranah interpretasi terhadap lagu keroncong. Hal itu yang sampai saat ini masih dipatuhi dalam musik keroncong agar dapat mencapai musikalitas yang ngroncongi.

Musik keroncong mempunyai konsep dasar pencapaian musikal yang sering diungkapkan oleh seniman keroncong dengan istilah ngroncongi. Ngroncongi merupakan istilah yang mengacu pada bahasa Jawa. Keroncong menjadi kata dasar, yang selanjutnya pada awal kata terdapat imbuhan "Ng-" dan di akhir kata mendapat imbuhan "-i", sehingga awalnya keroncong merupakan kata benda, beralih menjadi kata sifat setelah berubah menjadi ngroncongi. Pada hakekatnya, ngroncongi adalah musikalitas yang menjadi indikasi sifat khas musik keroncong. Ngroncongi tersebut akan tercapai apabila sesuai dengan estetika dan kultur musik keroncong.

Beberapa gejala musikal yang muncul dalam membentuk musikalitas yang 
ngroncongi bersifat subkonsep dan teknis. Gejala musikal yang tergolong subkonsep diantaranya ngglali; nyendaren; samenspelen; luk; gojek; dan mbesut. Gejala musikal yang bersifat teknis, diantaranya mbanyumili; sintiran; dan isenisen. Gejala musikal itu lebih sering diungkapkan oleh seniman keroncong yang eksis melestarikan musik keroncong di Surakarta.

Beberapa festival keroncong yang diselenggarakan saat ini banyak menyajikan penampilan penyanyi atau kelompok musik yang justru membuat masyarakat kehilangan arah dalam mengapresiasi musik keroncong. Realitasnya adalah terdapat penampil yang menggunakan instrumeninstrumen tidak seperti pada umumnya ansambel keroncong, menggunakan instrumen lengkap dalam ansambel keroncong, namun cara memainkan musiknya tidak secara karakteristik terasa ngroncongi; memainkan lagu yang populer saat ini, namun seolah diaransemen mendekati rasa keroncong, dengan menonjolkan permainan salah satu atau dua instrumen dalam ansambel keroncong; adapula kasus masing-masing instrumen secara prinsip sudah memainkan sesuai perannya dalam suatu instrumentasi lagu keroncong, namun motif dan cara memainkan instrumen tersebut tidak sesuai dengan keroncong pada umumnya. Kasus- kasus seperti ini membuat masyarakat yang mengapresiasi musik keroncong semakin bingung untuk memilah dan menilai sajian musik keroncong mana yang sebenarnya mempunyai kualitas musikal ngroncongi, dan mana yang tidak memenuhi rasa tersebut. Pandangan mengenai musik keroncong yang dianggap memenuhi kualitas musikal ngroncongi atau tidak sampai saat ini masih menjadi perdebatan yang tidak ada habisnya, karena gejalagejala musikal yang diimplementasikan oleh seniman keroncong belum dapat diapresiasi dengan baik.

Ada sebuah keprihatinan yang mendasar terhadap pemahaman masyarakat yang cenderung semakin menipis mengenai musik keroncong, khususnya hal-hal esensial dari sifat atau karakteristik musikalitas keroncong. Perkembangan musik keroncong saat ini oleh beberapa kalangan pecinta musik keroncong sering dinilai telah kehilangan arah (kebablasan) alias tidak ngroncongi lagi. Melihat feromenena ini penulis memandang perlu untuk mengetahui lebih mendalam tentang bagaimana hal-hal esensial dari karakteristik musik keroncong yang ngroncongi.

\section{A. Samen Spelen}

Samen spelen yang dimaksud dalam konteks musik keroncong merupakan kerja 
sama yang baik antar pemain keroncong. Istilah ini disinyalir para seniman keroncong berasal dari bahasa Belanda. Samen berarti bersama, sedangkan spelen artinya menabuh; bermusik; memainkan. Analogi yang digunakan oleh seniman keroncong di kota Solo adalah diibaratkan kerja sama dalam bermain sepak bola. Suatu tim sepak bola ketika menggiring, menjaga dan saling mengumpan bola hingga membangun interaksi yang baik antar pemain itulah yang dimaksud samen spelen. Pola pikir tersebut yang diimplementasikan oleh para seniman keroncong untuk bekerjasama, saling berinteraksi untuk membangun suatu interaksi musikal yang harmonis saat memainkan musik keroncong. Saling memperhatikan, dan menunjang satu sama lain, tidak menunjukkan virtuositas demi kepentingan pribadi.

Kekompakan antar pemain atau istilahnya samen spelen memang penting dalam etika bermain musik keroncong. Apabila pemain keroncong tidak dapat membaca notasi, maka mengoptimalkan kepekaan telinga atau feeling menjadi penting. Pemahaman mengenai etika-etika yang ada pada musik keroncong perlu disadari oleh setiap pemain keroncong untuk mencapai samen spelen. Setiap pemain keroncong biasanya mempunyai kompetensi untuk memainkan lebih dari satu instrumen keroncong, hal ini umumnya hanya sebagai pembelajaran untuk dapat memainkan instrumen lain, dan juga antisipasi apabila dalam suatu keadaan pemain ansambel keroncong sedang tidak lengkap formasinya. Berdasarkan pengalaman ketubuhan sesuai intensitas proses berlatih, maka setiap pemain mempunyai prioritas untuk memainkan satu instrumen yang dipelajari lebih mendalam secara fokus. Setiap personal nantinya akan fokus dengan pola permainan dan penempatan instrumentasinya. Apabila dilihat dari konteks musikal, dalam segi instrumentasi permainan antar pemain agar memenuhi rasa samen spelen mereka memainkan prinsip dari counter melody. Counter melody memang sudah lama diimplementasikan oleh para seniman keroncong tanpa mereka sadari, dengan tujuan untuk membangun harmonisasi suatu lagu. Hal ini dipertegas dalam tulisan Genichi Kawakami, dalam bukunya yang berjudul Arranging Popular Music: A Practical Guide, berikut kutipan dari tulisan tersebut,

The counter melody supports the melody. It thus plays an important role in arranging, and may be used in various ways. Filler and obligatto parts, for example are often variations of a counter melody. Its main functions is to strengthen the harmonic feeling by using a second melodic line, but it may also be used to give the arrangement a touch of 
individuality through the insertion of effective phrases. (melodi yang berlawanan menunjang suatu melodi, dengan demikian melodi yang saling berlawanan mempunyai peran penting dalam penggubahan musik, dan memungkinkan digunakan dalam berbagai cara, sebagai contoh bagian isian dan obligato juga sering menggunakan variasi melodi yang berlawanan. Fungsi utamanya adalah untuk memperkuat harmonisasi rasa dengan menggunakan garis melodi kedua, tapi itu juga memungkinkan untuk memberikan sentuhan keindividuan pada aransemen melalui penyisipan dari frasa efektif. (Kawakami, 1975:46).

Tempo juga salah satu unsur musikal yang nampak pada samen spelen, ketika antar pemain tidak saling mendengarkan, dan tidak bermain sesuai dengan tempo yang dibangun maka dianggap belom memiliki samen spelen atau antar pemain belum bisa kerjasama dengan baik. Sebenarnya banyak sekali fill in yang tidak tertulis pada notasi lagu tersebut, dan secara tidak disadari banyak pemain cak dan cuk yang memainkan fill in ketika perpindahan akord. Umumnya, ketika pemain cak dan cuk tidak membangun interaksi yang baik, maka fill in yang dibentuk tidak bisa cocok. Karena fill in yang dibangun instrumen cak dan cuk secara pola ritme dan melodi saling berkaitan sehingga membentuk suatu fill in sebagai penanda transisi akord. Apabila tidak membangun intensitas berpasangan dari awal, membutuhkan waktu lebih karena membangun satu melodi namun dimainkan secara bergantian penempatan ketukannya. Samen spelen tersebut bukan dibangun dengan suatu kesepakatan sebelum musik dimainkan, namun terbangun secara alamiah, dengan memperhatikan satu sama lain. Metodenya adalah mendengarkan referensi lagu yang ada, dan mencoba mencontoh secara otentik bunyi yang diperdengarkan lalu apabila telah memahami baru melakukan pengembangan.

\section{B. Ngglali}

Ngglali mempunyai kaitan erat dengan jajanan anak kecil berupa permen manis yang sering disebut gulali. Gulali yang dimasak dalam wajan tersebut dinilai mempunyai rasa kental, manis, dan lengket. Ketika gulali ditarik ke atas, maka lapisannya yang tertarik ke atas menyerupai lem. Dan ketika sudah matang dan dingin, maka tekstur permukaannya akan mengeras dan menjadi kental. Menurut Sapto, apabila dikaitkan pada konteks ngroncongi, ngglali adalah bagaimana seorang pemain biola ketika membangun melodi maupun improvisasi memberikan cengkok pada permainan biolanya untuk membangun kesan kemayu atau centil, untuk mengakomodir cengkok seperti itu 
menggunakan teknik glissando ${ }^{1}$ disertai perpanjangan nada yang stabil secara kualitas bunyi yang dihasilkan itulah yang dianggap ngglali. Ngglali yang dimaksud untuk memenuhi ngroncongi bukan suatu tolak ukur menilai kualitas permainan biola secara verbal kasat mata, melainkan bagaimana telinga dan perasaan dapat menerima dan imajinasi mereka terbawa oleh kesan rasa permen gulali tersebut.

Pemain biola keroncong dalam membangun suatu melodi tidak berorientasi penuh terhadap notasi biola dalam musik klasik. Kecenderungan melodi biola yang dimainkan dalam musik klasik lebih terkesan pakem, karena dimainkan sesuai dengan apa yang telah ditulis oleh seorang komposer musik klasik. Seorang pemain biola dalam ansambel keroncong lebih kepada merepresentasikan bunyi sesuai dengan perbendaharaan harmoni yang dimiliki selama mendengar lagu-lagu keroncong sebagai acuan, lalu proses latihan dan berdasar pada pengalaman empiris.
Suasana hati atau mood dalam hal ini juga mempunyai peran penting untuk menunjang bagaimana seorang pemain biola memainkan melodi yang berbentuk suatu cerita.

\section{Nyendaren}

Nyendaren yang dimaksud adalah mengambil analogi dari suatu layangan ketika diterbangkan ke udara, lalu apabila dibiarkan bertahan diatas akan menimbulkan efek bunyi yang konstan dan bergetar, bahkan suaranya rendah dan bulat. Teknik yang digunakan untuk mengakomodir bunyi flute yang nyendaren dengan memperhatikan embouchure ${ }^{2}$ flute tanpa adanya bocoran disela sela key atau lubang-lubang nada dalam middle joint (bagian dalam body) instrumen flute. Kualitas tiupan instrumen flute yang dirasa nyendaren lebih menitik beratkan kepada kualitas tiupan yang bulat, terutama pada nada-nada rendah, dan juga nada tinggi sesuai dengan tema melodi lagu.

\footnotetext{
${ }^{1}$ Glissando adalah teknik memainkan dua not yang berurutan pada satu senar dengan cara memetik not pertama saja lalu menggeser jari kiri dari not pertama menuju not berikutnya, tanpa mengurangi tekanan pada senar. (Kristianto, 2013:41).

${ }^{2}$ Embouchure adalah cara meniup pada alat tiup (Prier, 2014:42).
} 


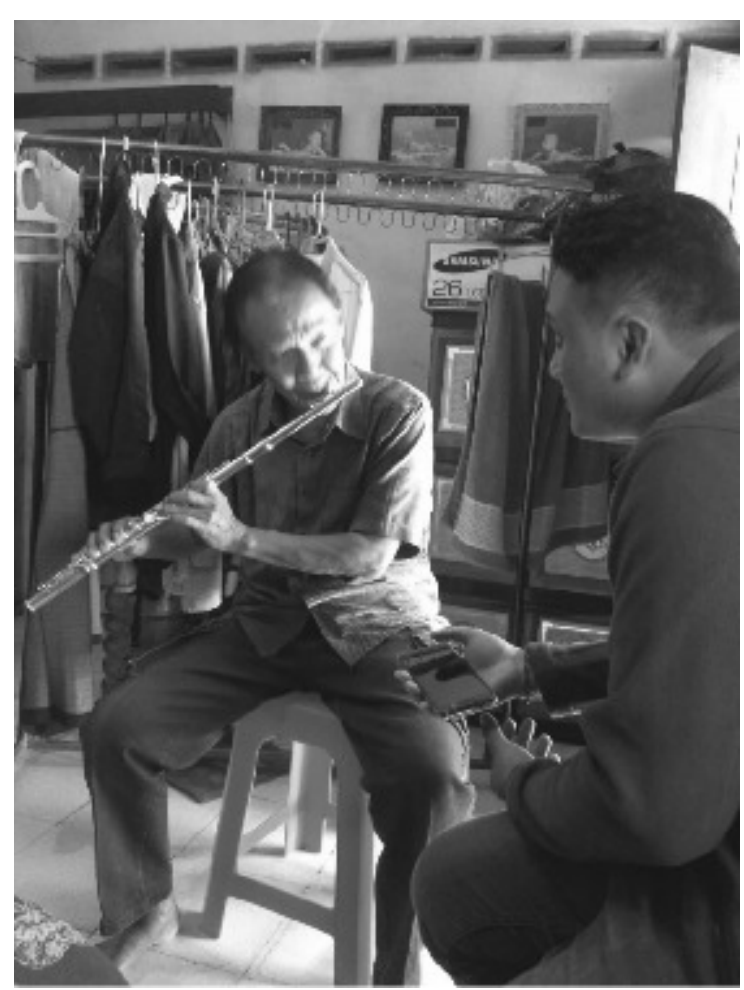

Gambar 1. Pak Sunarto mempraktekkan permainan flute keroncong yang nyendaren. (Foto Anastasia Selviana, 2018)

Teknis seperti ini menjadi hal yang krusial dan harus diperhatikan oleh pemain flute keroncong, karena sebelum membangun melodi, pemahaman akan kualitas bunyi tiupan yang dihasilkan menjadi aspek yang perlu disadari dan diperhatikan. Banyak kasus, pemain flute keroncong yang dianggap bagus ketika membangun suatu melodi penghantar menuju garis vokal, atau bahkan membuat isian disela-sela vokal, namun ketika produksi tiupan yang dihasilkan tidak merujuk kepada kualitas bunyi tiupan yang nyendaren, maka dianggap kurang ngroncongi. Faktor material dan kualitas alat yang digunakan juga sangat memperngaruhi produksi suara yang dihasilkan oleh instrumen tersebut.

\section{Mbesut}

Istilah mbesut juga sering diutarakan oleh para seniman keroncong, khususnya untuk membahas konteks cara menyanyi seorang penyanyi keroncong. Seorang penyanyi dikatakan mbesut apabila dapat memperindah kalimat lagu yang dinyanyikan dengan menyisipkan ornamen melodi vokal menggunakan teknik glissando. Menurut Sapto, cara menyanyi mbesut secara prinsip adalah merambat dari satu nada ke nada lain, baik menuju nada yang lebih tinggi, maupun ke nada yang lebih rendah. Seorang penyanyi ketika mbesut secara sadar paham bagaimana pemotongan suku kata dalam suatu kalimat lagu yang digunakan sebagai nada panjang untuk diisi dengan besutan tersebut.

\section{E. Luk}

Seorang penyanyi keroncong memiliki ciri khas dengan luk nya. Implementasi menyanyi dengan luk yang dimaksud dalam konteks ngroncongi berbeda dengan $l u k$ yang ada pada karawitan Jawa. Luk yang dimaksud dalam konteks 
ngroncongi adalah luwes -not luk tersebut maka teknik yang digunakan adalah legatto ${ }^{3}$.

Menurut Mini Satria, apabila penyanyi keroncong menyanyikan lagu keroncong hanya menyanyikan garis vokal seperti yang tertulis pada notasi tanpa luk, dianggap kurang manis dan kurang "ngroncongi”. Luk juga didasari oleh pembawaan masing-masing penyanyi, karena berbeda penyanyi, akan berbeda pula luk yang dihasilkan. Luk yang dimaksud dalam hal ini apabila ditarik dalam budaya musik barat secara prinsip merupakan dekorasi melodi berupa artikulasi yang sifatnya terdapat jalinan antar nada yang saling menyambung, tanpa terputus dalam suatu susunan melodi. Setelah itu untuk perpanjangan nada, not terakhir diberi vibrasi.

Cara menyanyi luk mempunyai dampak dalam melagukan keroncong, diantaranya melatih phraseringnya agar tepat. Sebagaimana yang dijelaskan oleh Machulan Baihaqi, apabila dalam suatu kalimat melodi tersebut nilai ritmenya panjang, maka seorang penyanyi harus tepat dalam melakukan teknik pernafasan agar tidak tersengal-sengal saat menyanyikan melodi dengan nada-nada panjang. Kestabilan tenaga dalam mengolah cara menyanyi dengan nada-nada panjang sangat diperlukan agar tidak merubah teknik demi menyiasati kehabisan nafas saat akhir frasa. Luk juga digunakan sepanjang menyanyikan suatu kalimat lagu. Salah satu teknik untuk menjaga kestabilan menurut Machulan Baihaqi adalah saat nada rendah mengambil nafas di leher, saat nada tinggi menggunakan pangkal leher. Ismanto merupakan salah seorang penyanyi yang dinilai tepat mengolah teknik tersebut, sehingga timbre ${ }^{4}$ nya tidak berubah, baik saat nada tinggi maupun nada rendah. Dengan kata lain tidak menyiasati nada tinggi dengan falsetto ${ }^{5}$.

\section{F. Gojek}

Interaksi musikal antara instrumen cak dengan cuk tidak lepas dengan permainan yang gojek. Istilah gojek merupakan adaptasi dari bahasa jawa yang dalam bahasa indonesia berarti bercanda. Apabila dikaitkan dalam konteks musik

\footnotetext{
${ }^{3}$ Legatto adalah teknik menyanyi/ memainkan sejumlah not dalam satu rangkaian atau satu frasa dengan cara semulus mungkin, Perpindahan not ke not berlangsung dengan rapat, tanpa jeda sesingkat apapun di antara not-not tersebut. (Kristianto, 2013:60).

${ }^{4}$ Timbre adalah warna bunyi (Kristianto, 2013:115).

${ }^{5}$ Falsetto adalah register suara tinggi, lebih tinggi dari suara kepala. Suaranga sangat tipis, namun tak kalah indahnya. (Prier, 2014:45).
} 
keroncong, gojek merupakan jalinan antara pola ritme dan melodi yang dibangun antara cak dan cuk, dengan dasar arpeggio dari akord yang digunakan. Ada satu hal yang unik ketika dua instrumen ini bermain bersama, karena terdapat perbedaan pola pikir dalam pengaplikasian akordnya. Contoh pengaplikasiannya adalah, dalam tangga nada $\mathrm{Do}=\mathrm{D}$ major, ketika cuk memainkan akord D Major, maka instrumen cak memainkan G major. Dengan kata lain saat cuk memainkan akord I, instrumen cak memainkan akord IV nya. Selanjutnya apabila instrumen cuk memainkan akord II, maka instrumen cak memainkan akord $\mathrm{V}$ nya. Interval yang digunakan dalam musik barat dinamakan perfect fourth. Tergolong interval perfect fourth, karena jarak antar nadanya adalah 3 whole tone, dan 1 semi tones.

Menurut Jeffry Chaniago, jalinan pola ritme dan melodi antara instrumen cak dengan instrumen cuk mempunyai perbedaan pengaplikasiannya, antara gaya Tugu; dengan gaya Solo. Teknik permainan instrumen cak dan cuk gaya Tugu menggunakan teknik strumming, sedangkan gaya Solo dengan cara sintiran. Teknik strumming yang dimaksud dalam permainan cak dan cuk gaya Tugu adalah dengan cara membunyikan beberapa senar sekaligus secara serentak, bisa menggunakan jari atau pick. Sedangkan permainan cak dan cuk gaya Solo menggunakan cara sintiran, secara pengimplementasian teknik yang digunakan adalah arpeggio, yakni membunyikan akord yang dimainkan not per not secara berurutan dalam suatu pola tertentu. Dua teknik yang berbeda tersebut secara otomatis juga akan berpengaruh pada fakta bunyi dari jalinan kedua instrumen tersebut.

Berikut ini merupakan salah satu contoh bagian dari jalinan interaksi musikal antara instrumen cak dan cuk keroncong yang dianggap memenuhi rasa gojek. Notasi yang akan digunakan oleh peneliti masih bersumber pada lagu “Keroncong Asli”yang dinyanyikan Ismanto dengan nada dasar $\mathrm{Do}=\mathrm{F}$ major yang direkomendasikan oleh beberapa buaya keroncong di Kota solo karena di dalam instrumentasinya terdapat bagian jalinan instrumen cak dan cuk yang gojek. Contoh notasi instrumen cak dan cuk yang gojek dalam lagu "Keroncong Asli" yang dinyanyikan Ismanto terdapat pada birama 9 sampai 14. Berikut transkripsi dari birama tersebut.

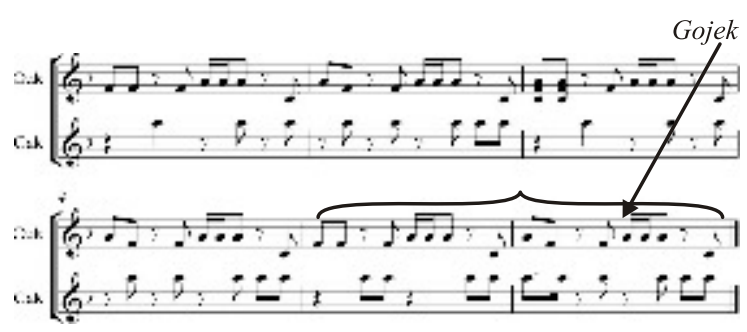

Gambar 2. Transkripsi jalinan interaksi musikal instrumen cak dan cuk yang gojek pada birama 9 sampai 14 . 
Bagian birama 9 dan birama 10 merupakan dua birama pada bagian akhir introduksi sebagai transisi menuju bait vokal. Birama 11 sampai birama 14 merupakan satu kalimat lagu dalam bait lagu. Pada bagian birama 9 sampai pada birama 12 jalinan pola ritme instrumen cak dan cuk cenderung konstan. Pola ritme dasar instrumen cuk dalam satu birama adalah ketukan pertama bernilai $1 / 2$ ketuk; ketukan kedua terdapat syncopasi bernilai $1 / 2$ ketuk, pada ketukan ketiga terdapat triplet dengan nada yang sama, ketukan ke empat terdapat syncopasi bernilai $1 / 2$ ketuk. Satu bentuk utuh dari pola ritme cak dimainkan selama 2 birama. Pola ritme instrumen cak diantaranya: pada birama pertama, ketukan pertama istirahat selama satu ketuk. Pada ketukan kedua terdapat not $1 / 4$ dengan nilai 1 ketuk. Pada ketukan ketiga birama pertama hingga ketukan ketiga birama kedua terdapat syncopasi dengan nilai $1 / 2$ ketuk. Ketukan ke empat birama kedua merupakan not bernilai $1 \frac{1}{2}$ ketuk. Penekanan jalinan pola insteraksi musikal antara instrumen cak dengan cuk yang dirasa gojek terletak pada birama 13 sampai birama 14. Sesuatu hal yang dianggap gojek dalam bagian tersebut adalah adanya perubahan pola ritme dari instrumen cak, dalam merespon pola ritme instrumen cuk yang cenderung konstan. Perubahan pola ritme instrumen cak dalam birama 13 sampai 14 adalah sebagai berikut, birama ke 13 ketukan pertama merupakan tanda istirahat selama satu ketuk, ketukan kedua merupakan not 1/2 ketuk. Ketukan ketiga tanda istirahat selama satu ketuk, dan ketukan keempat not bernilai $1 / 2$ ketuk. Birama 14 ketukan pertama merupakan not bernilai $1 / 4$ ketuk, nada ke 2 dan 3 dalam satu ketuk tersebut tidak dibunyikan, maka menyerupai bunyi syncopasi. Ketukan kedua dan ketukan ketiga terdapat syncopasi bernilai $1 / 2$ ketuk. Ketukan ke empat merupakan not bernilai $1 / 2$ ketuk.

\section{G. Isen-isen}

Isen-isen dalam konteks musik keroncong merupakan bagian yang dimanfaatkan untuk pemain instrumen depan dalam mengisi kekosongan nadanada panjang garis vokal; untuk mengisi akhir frase kalimat lagu vokal; dan sebagai melodi penghantar menuju bagian refrain. Isen-isen tersebut dimainkan oleh instrumen flute dan biola. Dua instrumen tersebut secara bergantian memberikan isen-isen untuk mengisi kekosongan dan juga membuat lagu lebih harmonis.

Prinsip yang dihindari oleh para pemain flute dan biola saat memberikan isen-isen, menurut Sunarto adalah, tidak memberikan dan membangun melodi yang sifatnya keluar dari konteks tema lagu tersebut dan bersamaan saat melodi vokal sedang dinyanyikan. Pemain flute dan biola 
boleh memainkan isen-isen saat garis vokal namun dengan cara hanya memainkan satu atau dua nada-nada panjang, misalkan melodi vokal memainkan nada do, maka isen-isennya bisa menggunakan cara invers atau balikan akord, dengan memainkan nada 3 (mi) sebagai balikan I; dan nada 5 (sol) sebagai balikan II. Setelah akhir kalimat lagu pada garis vokal barulah pemain flute atau biola merespon nada-nada panjang melodi vokal dengan memberikan isen-isen . Pertimbangan ini dilakukan agar penikmat lagu tetap terfokus pada melodi vokal yang berada pada garis depan untuk menyampaikan pesan dari lagu tersebut.

Berikut ini merupakan salah satu contoh bagian dari permainan flute dan biola keroncong yang dianggap sebagai bagian isen-isen. Notasi yang akan digunakan oleh peneliti masih bersumber pada lagu "Keroncong Asli" yang dinyanyikan Ismanto dengan nada dasar $\mathrm{Do}=\mathrm{F}$ major yang direkomendasikan oleh beberapa buaya keroncong di Kota solo karena di dalam instrumentasinya terdapat bagian isen-isen dari instrumen flute dan biola. Contoh notasi isen-isen yang dimainkan oleh instrumen flute dan biola dalam lagu "Keroncong Asli" yang dinyanyikan Ismanto terdapat pada birama sampai birama 15 sampai 19; dan birama 38 sampai birama 43. Berikut transkripsi dari birama tersebut.

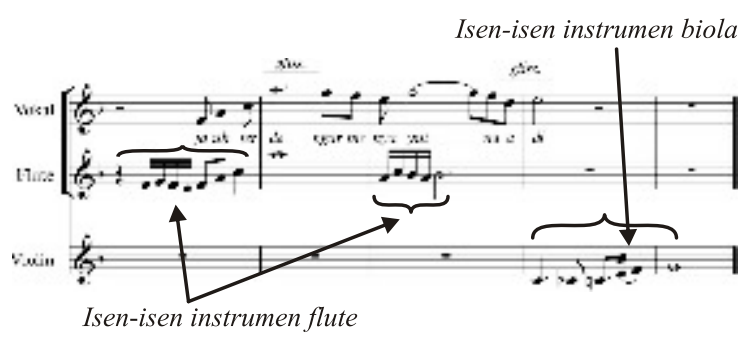

Gambar 3. Transkripsi bagian permainan instrumen flute dan biola saat memberikan isen-isen pada birama 15 sampai 19.

Pada birama 15 sampai 19 tersebut nampak adanya isen-isen yang dilakukan oleh instrumen flute dan biola dalam merespon melodi vokal. Isen-isen yang dimainkan oleh flute terletak pada birama 15 sampai birama 17, sedangkan instrumen biola merespon akhir kalimat lagu pada birama 18 sampai birama 19.

Isen-isen flute pada birama 15, ketukan pertama merupakan not istrirahat satu ketuk. Ketukan kedua adalah not 1/4 ketuk dengan susunan nada F-G-F-E; ketukan ketiga merupakan not $1 / 2$ ketuk dengan susunan nada F-A bertepatan dengan lirik vokal "ja-uh". Ketukan keempat merupakan not 1 ketuk bertepatan dengan kata "ter" dari kata terdengar dengan nada $\mathrm{C}$. Birama 16 bernilai 4 ketuk dengan nada $\mathrm{A}^{1}$ bertepatan dengan kata "de" dalam kata terdengar. Birama 17 ketukan pertama merupakan not $1 / 4$ ketuk dengan susunan nada $\mathrm{A}-\mathrm{C}-\mathrm{Bb}-\mathrm{A}$ bertepatan melodi vokal dengan lirik kata "nya-yut" dari kata menyayut. Ketukan kedua sampai keempat 
merupakan perpanjangan nada selama 3 ketuk dengan nada $\mathrm{Bb}$ sebagai transisi menuju kata "na-di".

Isen-isen yang dimainkan instrumen biola terletak pada birama 18 sampai birama 19 untuk merespon bagian akhir kalimat lagu vokal. Birama 18 ketukan pertama bernilai 1 ketuk dengan nada $\mathrm{C}$ bertepatan dengan kata “-di” dalam kata na-di. Ketukan kedua juga not bernilai satu ketuk dengan nada B. Ketukan ke 3 merupakan not 1/4 ketuk dengan nada ke 2 dan 3 tidak dibunyikan seolah seperti syncopasi dengan nada C-E. Ketukan keempat merupakan not 1 ketuk dengan nada F. Birama 19 merupakan not bernilai 4 ketuk dengan nada G. Berikut ini merupakan transkripsi bagian yang dianggap isen-isen dari permainan flute dan biola, terletak pada birama 38 sampai birama 43 .
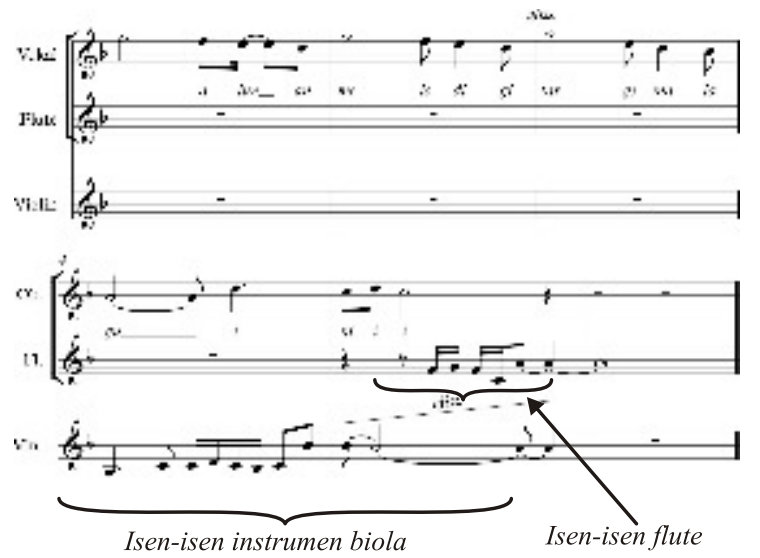

Gambar 4. Transkripsi bagian permainan instrumen flute dan biola saat memberikan isen-isen pada birama 38 sampai 43.
Pada birama 38 sampai 43 instrumen flute dan biola memberikan isen-isen dalam melodi vokal bagian reffrain. Penekanan pemberian isen isen terletak pada birama 41 sampai birama 43. Instrumen flute memberikan isen-isen setelah kata "i-ni" dalam kalimat lagu melodi vokal. Ketukan pertama merupakan istirahat selama 1 ketuk. Ketukan kedua merupakan syncopasi 1/2 ketuk dengan susunan nada F-G. Ketukan ketiga adalah not $1 / 4$ ketuk dengan nada ke 3 tidak dibunyikan dengan susunan nada F-CA. Ketukan ketiga merupakan not 1 ketuk dengan nada perpanjangan dari ketukan kedua, yakni nada A. Ketukan pertama birama 43 merupakan not bernilai 4 ketuk yang merupakan perpanjangan nada dari not sebelumnya, yakni nada A.

Isen-isen yang dimainkan oleh instrumen biola terlatak pada birama 41 sampai birama 42. Ketukan pertama adalah not bernilai $1 \frac{1}{1} 2$ ketuk dengan nada $A$ bertepatan dengan garis vokal saat suku kata "-gu" dalam kata la-gu. Ketukan kedua merupakan not bernilai $1 / 2$ ketuk dengan nada $\mathrm{C}$ bertepatan dengan perpanjangan nada pada kata "-gu”. Ketukan ketiga merupakan not bernilai $1 / 4$ ketuk dengan susunan nada C-D-C-B tepat bersaman dengan garic vokal saat suku kata "i-“" dalam kata ini. Ketukan keempat merupakan not bernilai 1/2 ketuk dengan nada C-Bb. Pada birama ke 42 ketukan pertama merupakan 
not bernilai $1 / 2$ ketuk dengan nada $\mathrm{Bb}$ tepat bersamaan dengan melodi vokal dengan kata "-ni” dalam kata i-ni. Ketukan kedua hingga ketukan keempat merupakan not bernilai $31 \frac{1}{2}$ ketuk dengan nada yang sama, yaitu nada A tepat bersamaan dengan perpanjangan nada suku kata “-I” dalam kata "i-ni”.

\section{H. Mbanyumili}

Mbanyumili yang dimaksud dalam konteks permainan gitar keroncong analoginya seperti air yang mengalir secara konstan dan tidak terputus putus. Pada pengimplementasian pola pikir mbanyumili terhadap instrumen gitar, sebenarnya tidak secara konstan dan monoton menggunakan pola ritme yang sama, dan berjalan mengikuti alur proggresi akord dlam suatu lagu, melainkan pemain gitar keroncong juga memainkan sinkopasi, chromatic approach untuk mencari nada terdekat sebelum menuju ke target not. Menurut Tukiyo, apabila dibedah secara teknis, misalnya gitar sedang memainkan akord D major, pemain gitar umumnya tidak memainkan akord tersebut secara bersamaan dengan cara strumming. Pemain gitar keroncong memainkan dengan cara memetik senar satu persatu atau arpeggio, sesuai dengan nada yang menjadi elemen pembentuk suatu akord tersebut. Maka, pemain gitar ketika memainkan akord D major, dia memainkan nada D-F\#-A, yang dimainkan secara bergantian secara ascending dan descending membangun suatu jalinan pola ritme dan melodi untuk menuju ke akord berikutnya. Sesekali terdapat sinkop dan chromatic approach terlebih pada posisi akord dominant sebagai fill in.

Berikut ini merupakan salah satu contoh bagian dari permainan gitar keroncong yang dianggap memenuhi rasa mbanyumili. Notasi yang akan digunakan oleh peneliti masih bersumber pada lagu "Keroncong Asli" yang dinyanyikan Ismanto dengan nada dasar $\mathrm{Do}=\mathrm{F}$ major yang direkomendasikan oleh beberapa buaya keroncong di Kota solo karena di dalam instrumentasinya terdapat bagian gitar yang mbanyumili. Contoh notasi gitar yang mbanyumili dalam lagu "Keroncong Asli” yang dinyanyikan Ismanto terdapat pada birama 5 sampai birama 12. Berikut transkripsi dari birama tersebut.

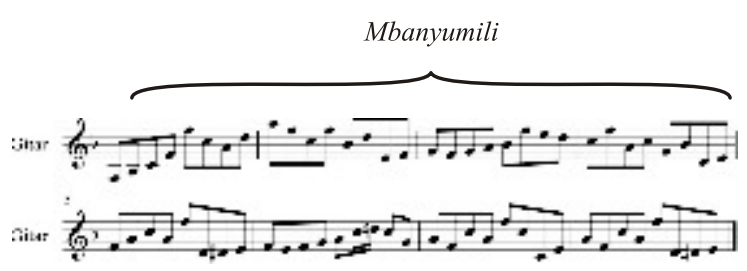

Gambar 5. Transkripsi permainan gitar keroncong yang mbanyumili pada birama 5 sampai 12 . 
Birama 5 sampai dengan tersebut dimainkan oleh gitar pada bagian introduksi. Pada bagian ini gitar berperan sebagai rhytm section. Teknik yang digunakan alternate picking, dengan teknik memetik senar ke bawah (downstroke) dan ke atas (upstroke) secara konstan. Proggresi akord dalam birama 5 sampai birama 12 adalah I-IV-V-I atau secara chord qualitynya adalah F-BbC-F. Gitar dalam hal ini memainkan triad atau chordtones dari tiap unsur akord yang dimainkan. Pada birama 5 dan birama 6 memainkan wilayah Akord F Major, unsur nada yang digunakan F-A-C-F-F ${ }^{1}-\mathrm{C}-\mathrm{A}-\mathrm{E}$ dan $\mathrm{A}^{1}-\mathrm{F}^{1}-\mathrm{C}-\mathrm{E}-\mathrm{Bb}^{1}-\mathrm{D}-\mathrm{E}-\mathrm{F}$. Unsur dalam tangga nada $F$ major adalah F;G;A;Bb;C;D;E;F. Melihat dari susunan melodi yang digunakan pada birama 5 dan birama 6, nada yang digunakan F-A-Bb-CD-E, atau do-mi-fa-sol-la-si.

Birama ke 7 adalah memainkan unsur akord $\mathrm{Bb}$. Susunan melodi yang digunakan adalah G-F-G-A-Bb-F ${ }^{1}-\mathrm{E}-\mathrm{D}$. Melihat susunan melodi yang digunakan, nada yang digunakan Bb-D-E-F-G-A, atau do-mi-fi-sol-la-si. Ada satu nada yang digunakan sebagai chromatic approach, yaitu nada $E$ atau fi yang berfungsi sebagai passing note atau jembatan menuju nada $\mathrm{D}$ (mi). Pada birama ke 8 memainkan wilayah akord C major. Susunan melodinya adalah C-F - A-C-G-Bb-D-E atau do-fa-la-do-solle-re-mi. Ada satu nada yang digunakan sebagai penanda akord dominant 7 th, karena nada ke tujuh turun setengah menjadi $\mathrm{Bb}$ atau le. Birama 9-12 memainkan wilayah nada $\mathrm{F}$ major, dengan ada variasi triplet, pada birama ke 10 ketukan ke 3, dengan susunan nada A-C-E atau mi-sol-si. Maksud dari adanya sisipan triplet pada pola ritme not bernilai $1 / 2$ ketuk tersebut agar adanya variasi pola ritme.

\section{Sintiran}

Cara memainkan instrumen cuk dengan cara sintiran menurut beliau jaman dahulu memang mengadaptasi dari pola permainan kentongan yang ada di pos ronda. Jaman kemerdekaan dahulu instrumen keroncong belum selengkap sekarang. Seniman keroncong pada masa itu juga belum semuanya dapat membeli dan memiliki alat musik. Maka, alat yang digunakan untuk menggantikan peran cuk pada masa itu adalah kenthongan, namun dengan pola ritme seperti permainan cuk pada musik keroncong. Setelah seniman keroncong dapat memiliki instrumen pola ritme yang awalnya dimainkan dengan kenthongan ditransformasikan ke alat musik cuk.

Sunarto menjelaskan bahwa sintir, atau sintiran yang dimaksud adalah memetik senar sesuai triad, atau tri nada suara yang menjadi elemen dalam membangun suatu akord. Senar yang dibunyikan bukan dengan teknik strumming 
atau digenjreng, melainkan tri nada suara tersebut dipetik dengan cara mengurai satu persatu akoard yang dimainkan secara arpeggio dengan pola ritme not $1 / 8$ dan juga variasi ritme berupa triplet.

Berikut ini merupakan salah satu contoh bagian dari permainan cuk keroncong yang dianggap cara memainkan nya sintiran. Notasi yang akan digunakan oleh peneliti masih bersumber pada lagu "Keroncong Asli" yang dinyanyikan Ismanto dengan nada dasar $\mathrm{Do}=\mathrm{F}$ major yang direkomendasikan oleh beberapa buaya keroncong di Kota solo karena di dalam instrumentasinya terdapat bagian cuk yang sintiran. Contoh notasi cuk yang mempunyai cara memainkan sintiran dalam lagu "Keroncong Asli" yang dinyanyikan Ismanto terdapat pada birama 5 sampai birama 12. Berikut transkripsi dari birama tersebut.

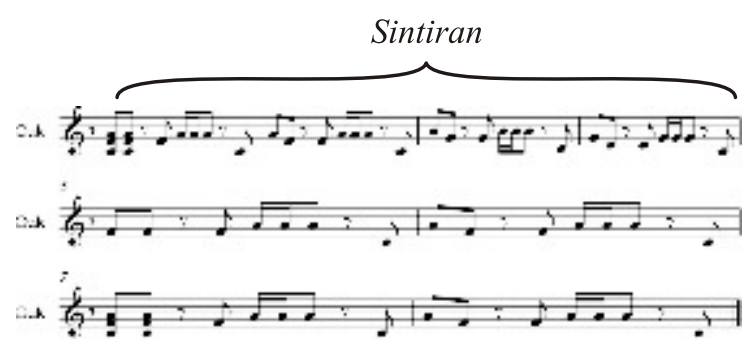

Gambar 6. Transkripsi permainan cuk keroncong yang menggunakkan cara sintiran pada birama 5 sampai 12.
Pada dasarnya pola ritme permainan cuk sintiran dimainkan dengan konstan dari birama 5 sampai birama 12. Ketukan pertama dimainkan dengan not $1 / 2$ ketuk. Ketukan kedua terdapat syncopasi $1 / 2$ ketuk. Ketukan ketiga merupakan triplet. Ketukan ke empat terdapat syncopasi $1 / 2$ ketuk. Pada lagu tersebut untuk setiap tingkatan akord Do maupun transisi dari akord lain menuju Do, cara memainkannya dengan strumming dalam bentuk akord sebagai aksentuasi.

Pada birama 5 dan birama 6 memainkan wilayah akord $\mathrm{F}$ major dengan susunan nadanya adalah memainkan not $1 / 2$ ketuk pada nada A-F, lalu terdapat sinkopasi 1/2 ketuk menuju nada F pada ketukan kedua, ketukan ketiga terdapat triplet dengan nada yang sama yakni A. Pada ketukan ke empat terdapat sinkopasi bernilai $1 / 2$ ketuk pada nada C. Pada birama ke 7 memainkan wilayah nada $\mathrm{Bb}$ dengan susunan nadanya adalah memainkan not $1 / 2$ ketuk pada nada Bb-G, lalu terdapat sinkopasi $1 / 2$ ketuk menuju nada $G$ pada ketukan kedua, ketukan ketiga terdapat triplet dengan nada yang sama yakni Bb. Pada ketukan ke empat terdapat syncopasi bernilai $1 / 2$ ketuk pada nada D. Pada birama ke 8 memainkan wilayah nada $\mathrm{C}$ major dengan susunan nadanya adalah memainkan not $1 / 2$ ketuk pada nada G-E, lalu terdapat sinkopasi $1 / 2$ ketuk menuju nada E pada ketukan kedua, ketukan ketiga terdapat triplet dengan nada 
yang sama yakni G. Pada ketukan ke empat terdapat sinkopasi bernilai $1 / 2$ ketuk pada nada C. Pada birama ke 9 sampai birama 12 memainkan pola ritme dan melodi seperti pada birama 5 dan 6.

Lagu "Keroncong Asli" yang dinyanyikan oleh Ismanto tersebut mengandung elemen-elemen pembentuk kualitas ngroncongi yang sangat kompleks di berbagai bagian lagu. Notasi yang digunakan oleh penulis dalam kasus di atas lebih spesifik pada contoh masing-masing elemen. Berbagai elemen tersebut merupakan salah satu contoh perwujudan dari analogi suatu pola keseharian; teknik; dan sampai kepada persoalan interaksi musikal dari interpersonal. Analisa peneliti diatas juga membuktikan bahwa mengidentifikasi persoalan kedalaman wilayah rasa dapat diakses selama fakta bunyi secara auditif masih dapat diterima oleh telinga. Oleh karena itu, berbicara kualitas musikal yang ngroncongi bukan merupakan suatu kualitas musikal yang bersifat abstrak, imaginatif, melainkan dapat diidentifikasi dan dipelajari sebagai suatu pengetahuan bagi generasi seniman keroncong yang ingin melestarikan musik keroncong dengan tidak meninggalkan elemen-elemen yang merupakan esensi dari ngroncongi.

\section{Kesimpulan}

Ngroncongi merupakan suatu musikalitas yang menjadi indikasi sifat khas musik keroncong. Musikalitas yang ngroncongi dikonstruksi oleh elemenelemen penting untuk membangun rasa musikal ngroncongi. Rasa musikal ngroncongi dikonstruk oleh elemen musikal seperti yang telah dibahas diatas, yaitu samen spelen; ngglali; nyendaren; mbesut; luk; gojek; isen-isen; mbanyumili; dan sintiran. Elemen elemen tersebut saling bersinergi untuk mengakomodir musikalitas yang ngroncongi. Elemen yang bersifat pola ritme adalah sintiran, mbanyumili, dan gojek. Elemen dalam teknik permainan yang bersifat ornamentasi adalah ngglali; mbesut; luk; nyendaren; dan isen-isen. Sedangkan elemen samen spelen berupa interaksi musikal antar pemain dengan cara saling memberikan umpan secara musikal. Elemen-elemen tersebut merupakan hasil pengetahuan secara emik dari seniman keroncong yang direpresentasikan secara musikal untuk membangun musikalitas yang bersifat ngroncongi. Apabila beberapa elemen musikal tersebut tidak terpenuhi, meskipun salah satu elemen saja, maka musikalitas yang dibangun oleh suatu ansambel keroncong saat memainkan lagu, tidakngroncongi. 
Bayu Raditya Prabowo : KERONCONGKU, NGRONCONGI

\section{Daftar Pustaka}

Kawakami, Genichi. Arranging Popular Music A Practical Guide. Japan: Yamaha Music Foundation, 1975.

Kristianto, Jubing. Gitarpedia Buku pintar Gitaris. Jakarta: PT. Gramedia Pustaka Utama, 2013.

Prier SJ, Karl Edmund . Kamus Musik. Yogyakarta: Pusat Musik Liturgi, 2014.

Sunarto, Bambang. "Sholawat Campurngaji Studi Musikalitas, Pertunjukan dan Makna Musik Rakyat Muslim Pinggiran”, Laporan penelitian Institut Seni Indonesia Surakarta, 2006. 